\title{
Research on the Method of the Information Management of Engineering Project Construction process Quality Based on the Mobile Phone APP
}

\author{
Jiang pengming ${ }^{1}$, Zhang jing ${ }^{2}$, Yu shuan ${ }^{3}$, Cui xian ${ }^{4}$ \\ ${ }^{1}$ Jiang PengMing, Jiangsu University of Science and Technology ,ZhenjiangJiangsu ,China \\ ${ }^{2}$ Zhang Jing, Jiangsu University of Science and Technology , ZhenjiangJiangsu ,China \\ ${ }^{3}$ Yu shuan , Zhenjiang Jiangsu ,China \\ ${ }^{4}$ cui xian, Zhenjiang Jiangsu, China \\ a896565684@qq.com, b814316029@qq.com, ${ }^{\text {c2 } 21788356 @ q q . c o m ~}$ \\ d469631954@qq.com
}

Keywords: Engineering Quality, Quality control, Information management.

\begin{abstract}
In this paper, in the environment of the construction quality of the project management action is being undertaken and the environment "Internet + " action plan, construction quality from the current situation, analyzes problems of quality of the project at this stage, based on the fact of that the quality of construction projects and the exchange of information are most relevant, the author proposed the establishment of a practical, economical, efficient and effective mobile APP for the construction process quality control information. In this paper, according to Construction Quality Control PDCA principle established Announcement module, the planning phase module, the module inspection stage, the implementation stage module, disposal phase module, service platform module six functional modules, to build model for the entire system structure and six modules APP system model, in order to achieve the purpose of quality control of the construction process.
\end{abstract}

\section{Introduction}

Since the second half of 2014, the Ministry of Housing and Urban-Rural Development of the People's Republic of China to carry out a comprehensive project quality control operations, objectively speaking, the quality of our construction, although controlled, but the situation is not optimistic, there are still many problems. In some large projects, information exchange problems caused by engineering changes and errors; traditional construction in more than half of the problems are related to the exchange of information in accordance with relevant international statistics; exchange of information directly or indirectly lead to an increase of $10 \%-33 \%$ of the cost has occurred, and even lead to total investment increased by 3\% -5\%. The rapid development of the Internet, under the requirements of fast information exchange large cut of the environment, we must change the traditional way of communicating, the general quality of the information management has been unable to achieve the user wishes to obtain quality information anytime, anywhere. With the proposed rapid covering communications technology and LTE 4G high-speed broadband wireless networks, Internet + action plan and popularity of smart phones, smart phones instead of computers to handle daily affairs are more easier and faster. Visible, return itself to establish a practical construction enterprises, economic, efficient and effective mobile APP model for quality control of information in favor of quality control, it is conducive to the building housing the Ministry of Construction Quality Control. According to China Internet Network Information Center released data show that as of the second half of 2014, China's mobile Internet users use rate of $83.4 \%$, for the first time beyond the traditional PC usage, the phone has become the largest Internet terminal device, responsive to the needs of the public, the establishment of a practical, economic, efficient and effective mobile APP model for quality control of information will inevitably be more effective, so it does not require a fixed camera, information gathering more flexible, large-scale and low cost, to achieve a network-based mobile phone to mobile phone in real time quality information 
control system, making the whole system has mobility, timeliness, flexibility and control. In the era of $4 \mathrm{G}$ network environment, significantly increase the transmission speed and processing performance of the mobile phone network, this phone quality control APP will have a broader outlook is conducive to the sound development of the construction industry.

\section{Concept and Significance of Research}

Quality control from the status quo at home and abroad can be seen from the combination of laws and regulations to regulate economic means, to integrate Internet technology development system model, the use of information technology tools for quality control has become the future trend of development, but China's information technology is currently dependent Information Management is a PC with immovable property malpractice, in order to solve this problem, to develop a mobile phone-based APP quality control software can effectively compensate for deficiencies of the PC. Mobile APP is a mobile application, all applications are run on mobile devices, which aid to support mobile Internet technology, rely on coverage and the development of smart mobile terminals LTE high-speed broadband wireless networks in recent years, showing a mobile phone APP the explosive growth of the phenomenon, every day, all kinds of APP be exploited, it is gradually penetrated into all walks of life. According to market research firm Juniper Research Report: 2015, users downloaded the software for smart phones will reach 25 billion times, obviously, all walks of life full of mobile applications will become our lives an indispensable part of the work. For example, once held in 2010 Taipei International Flora Exposition game, called "Flower Expo", Taipei City Department of Transportation and technology companies for the development of the Flower Fair IOS version and Android version of the smartphone application APP "flower Hiroyuki "two months it was downloaded 49,000 times.

April 25, 2011 HuaBoHui operations end, the Taipei government LBS positioning technology combined with GPS (Global Positioning System, Global Positioning System) to continue the implementation of traffic information smartphone apps APP expansion and development, called "Taipei Good OK" .

Thought refer to the "Taipei Good Line" and "Flower Expo line", the author proposes a project based on the quality of the construction process of the mobile phone APP control information system.

\section{System Design}

System Design Concept. Refer to the "Process", "role", "activity" three elements of design. The author proposed based on the quality phones APP projects control information system can refer to "process", "role", "activity" three elements of the design. The role of operational processes and decomposition portfolio activity, the flow of the processing activities, the activities included in the process, these three elements is the basis for system design."Process" is the process of standardization of project quality management and business operation process; the "role" is the project management and business process (or processes) operating executive; "activity" is the project quality control and core business processes, project quality control is one of the most important information design part. In the system, the "role" covers almost all corporate management and staff of business operations layer, because the role related to the mandate authority, so the system of "role" design should be standardized as much as possible and meticulous, the only way to Role and mandate to achieve the appropriate permissions to correspond to each other, but also to maintain user-defined roles this special feature design of the tool, in order to achieve a flexible permission settings. In addition, pay attention to the role of cross-cutting issues, sometimes circumstances several "roles" belong to the same person, such as: project manager "role", if there is no deputy project manager on the project, the project manager may serve two characters, it is possible to have two operating execute permissions roles. From the management to the underlying operating personnel should have different rights, different roles privileges can only see the contents within their own level permissions, the permissions higher operability stronger, such as the project 
manager can choose to turn off message alerts, DND mode, or select a fixed period a unified view, can also see the progress of the project at any time, to understand the scene where one step, while the foreman in charge of solving the problem and the relevant technical staff does not have this feature, the problem will not solve every certain time will remind a specific time set by the higher authority of people, such as construction companies time duration, the project manager can set a shorter reminder period. Also note that the system is that the user must be able to apply themselves in the process according to the needs of business, decomposition, combination of sub-segment indicators.

The overall design system. According to the actual construction process, the paper quality of the project will be based on the principle of PDCA process control APP construction works roughly divided into the following functional blocks: Announcement module, the planning phase module, the module inspection stage, the implementation stage module, disposal phase module, Service Platform Module 6 functional modules.

Announcement module. Announcement module main function is to publish notice of the project department, all project-related personnel in the duties and powers can browse through this information APP timing chart as shown Fig1:

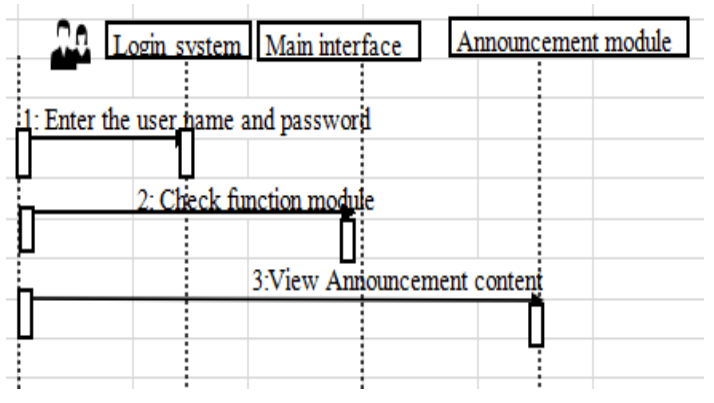

Fig. 1 :the Timing Diagram of Announcement

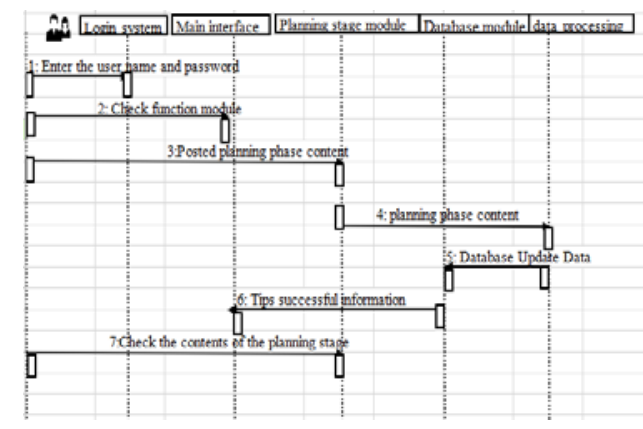

Fig.2: the Timing Diagram of Planning phase

The planning stage module. Plan stage is uploaded construction permits have been handled better, drawings and technical tests Mixed data, project quality plan and other information documents, project-related personnel in the duties and powers of the relevant information can be viewed through the APP, a comprehensive understanding of project case, construction plan to do the preparatory work, the planning phase timing diagram as shown Fig.2.

Implementation phase module. Implementation phase module content includes two aspects, one is ready to control the quality of construction, including construction workers, materials, machinery and equipment, site preparation and inspection, construction technology data preparation; on the other hand is the construction process quality control, quality control of the construction process It can be divided into two sub-templates, one for process and quality control of the hidden works, and the other is the design changes and modifications drawing quality control. Implementation phase timing chart as shown below:
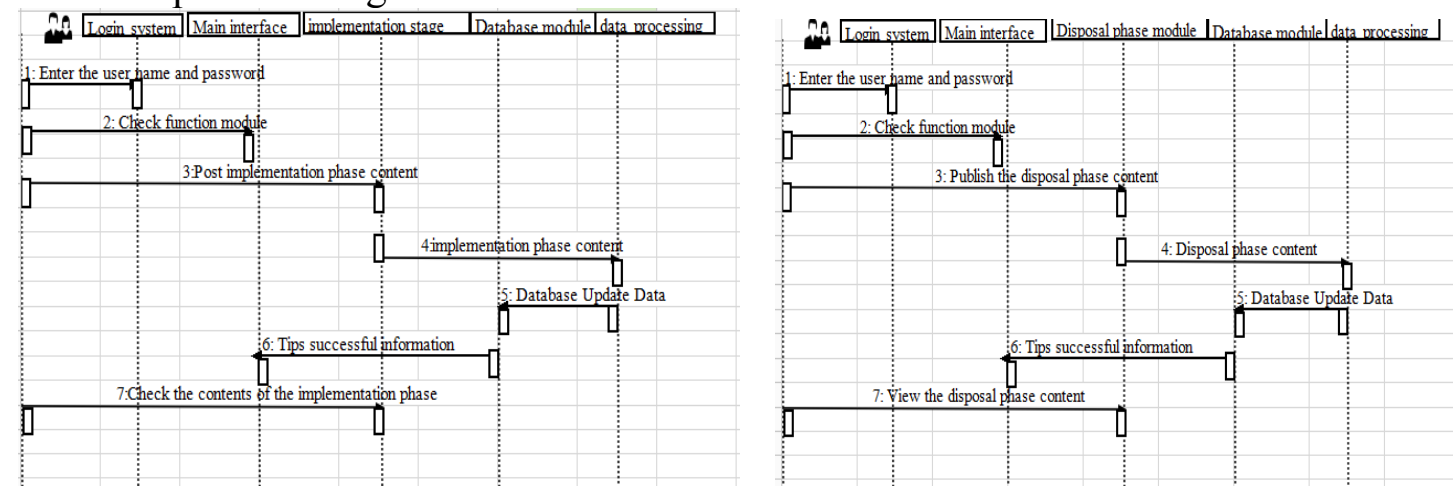

Fig.3:the Timing Diagram of Implementation phase Fig.4:the Timing Diagram of Checking phase

Checking stage module. After the implementation phase of the work has been the intermediate products in the project is a branch or sub-project, this time the contractors need to complete the 
self-test, self-test report after qualifying, while the relevant contractor staff should self-test Eligible entities quality information and pictures or videos uploaded by APP, self-qualified contractor, you can publish news announcement announcement module, Supervisor see good acceptance after the announcement related personnel ready, after receiving the formal application for the quality of the contractor inspection, so that the control of the construction period and claims very favorable acceptance Supervisor and submitted by APP after passing relevant information, but also failed to submit relevant information for rectification, until qualified to enter the unit, individual, project acceptance, for the Some acceptance process involves a third party, fourth party or even more parties, the parties can take advantage of this section APP empathy view the progress and acceptance, and timely prepare for participation and acceptance, therefore, this section APP can be used not only the construction side, Supervisor, Related departments construction side, government supervision departments, etc. can also be used to check phase timing chart as shown Fig.4.

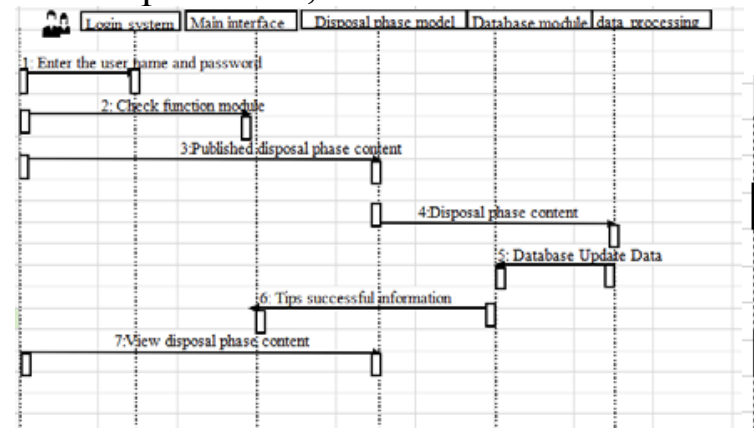

Fig.5: the Timing Diagram of Disposal phase

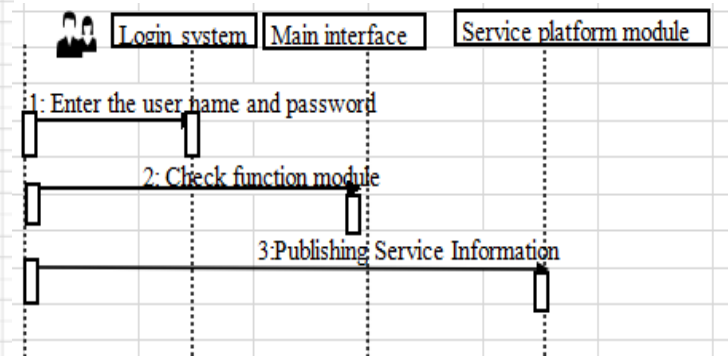

Fig.6: the Timing Diagram of Service phase

Disposal phase module. Disposal phase module is aimed primarily a legacy of quality problems, this module are not independent, it is closely related to the above-mentioned several modules for several stages of the problems and timely rectification, upload, update information at any time you can view the quality of management It is handling the case, in favor of progress and schedule control.timing chart as shown Fig.5 .

Service Platform Module. Daily life and related service platform for project staff are closely related, similar to real-life logistics department, is to protect the front of the functional modules, the service platform module is mainly released some routine service information, such as construction workers certain to please Logistics service messages receive life benefits like Mid-Autumn Festival, the timing diagram is shown Fig.6 .

Interface Design and login. Interface design concise and clear, the system to set the default password, you can change your password after the user logs on their own, and permissions design, each log based on the level.

Database Design. The database can use MySQL database, MySQL is an open source relational database management system, with the ability to handle large data, very suitable for database access on the Internet, the current version of MySQL provides a very rich and useful features, features fast access the system is simple to use, reliable and easy-to-use features.

\section{Conclusion}

Quality is an eternal theme of construction management, customer satisfaction is the eternal pursuit of the construction market. Thus, building construction companies must strictly to good quality, but because the quality of construction projects have an impact on many factors, quality fluctuations, the quality of concealment and final inspection of the limitations of these major features, so how quickly and effectively solve the quality problem is particularly important, I believe that the basis to enhance the quality of the project itself should return to construction companies to establish a practical, economical, efficient and effective phone-based APP information engineering project quality control software helps engineering quality of governance. 


\section{References}

[1] F.S. Zhang. quality work project quality management action research. Construction Industry, 2015 (3): 26-29

[2] C.H. Qin. Practice and Exploration Project Management Information Building models and methods . Construction technology, 2005 (2): 25-27

[3] Y.N. Zhang, Y. Lu, L.M. Zheng. design and development of Android based phones remote video surveillance system. Journal of Computer Applications, 2013 (S1):.. 283-286

[4] Mobile App prospects and development bottleneck of. given attention COMPUTER (Theory), 2014 (3): 69-70

[5] J.G. Yang. management and control of the construction process - study .quality control methods Shandong Industrial Technology, 2013 (10): 118

[6] D.H. Zhang, M.M. Chen, X.F. Zhang, J. Ma, Y.Y. Jiang. basis based on the campus network platform and flat refined management .software, 2014 (8): 59-62

[7] WEI hole, Qiu Xiaolin, Chen Ting quality management of construction projects. Science and Technology Information, 2012 (33): $368+415$

[8] Liu Jihua quality of water conservancy construction process control . Gansu Agriculture, 2013 (8): $50+52$

[9] Liu Yan On the project management information system construction method. Qinghai Transportation Research, 2005 (4): 4-5 + 10

[10] Some thoughts about Dan Perspective of traditional media, new media response measures .News Research Guide, 2015 (2): $64+84$

[11] Peng Yong virtual enterprise collaboration model for remote monitoring of the production process.Computer Applications, 2005 (7): 1707 a 1710

[12] Linyong Min, Zhao Shuang, Chen Hong of new information life-cycle management research networking technology based projects . e-commerce, 2013 (8): 43-44

[13] Lu Xu construction quality control .Chinese and foreign entrepreneurs, 2013 (31): 220-221

[14] Chen Kaiping. Quality building construction process control . charm China, 2011 (7): 56-58

[15] Jin Yan process of construction project based on the quality of ISO9000 standard model.Control Technology Management Research, 2014 (10): 202-205

[16] Chang Jin Ling Information System Development Quality Management. Information Science, 2001 (9): 976-991

[17] Zhouchong Hua, high for the Gang, Xu Chen, Su Zhizhe planning Smartphone App based traffic information service system. Traffic \& Transportation (Academic Edition), 2012 (2): 76-79

[18] On the information construction of the Palace of flat highway project cost management of the network. Construction \& Design, 2012 (6): 194-196

[19] The Impact of Mobile Zan Peas Social Media on College Students. Xichang College (Social Sciences), 2015 (1): 128-131

[20] Ding Shizhao Construction Project Management . fourth edition. Beijing: China Building Industry Press, 2015.4: 180-182 
[21] Qiuguo Lin, Gong Li Ming, Sunzheng Mao and other project management . second edition Beijing: China Electric Power Press, 2014.7: 101-116

[22] I beat. Various stages of commercial residential equipment engineering project management and control . Guangzhou, South China University of Technology .2012

[23] Chendian Long based in Harbin Youth Federation Discuz framework App system design and implementation. Changchun, Jilin University .2015

[24] Ka Chi Lam, S.Thomas Ng A cooperative Internet-facilitated quality management environment for construction.Automation in Construction, 2006 (1):. 1-11

[25] Frank Boukamp, Burcu Akinci .. Automated processing of construction specifications to support inspection and quality control .Automation in Construction, 2007 (17): 90

[26] DEVXStaff.25Billion Mobile App Downloads by 2015 [EB / OL] .2010 [2012-04-10] .http:? //www.devx.com/DailyNews/Article/45185 Trk= DXRSS_LATEST. 